\title{
Menjadi Scholarly Communication Librarians
}

\author{
Kristina \\ Sekolah Tinggi Ilmu Ekonomi Indonesia (STIESIA) Surabaya \\ kriztinasari@gmail.com
}

\begin{abstract}
Abstrak
Komunikasi ilmiah menjadi trend baru baru bagi dunia perpustakaan. Meskipun jika ditelaah komunikasi ilmiah bukanlah hal baru dalam dunia perpustakaan perguruan tinggi karena perpustakaan sudah terlibat di dalamnya. Komunikasi ilmiah merupakan proses komunikasi pencipataan karya tulis ilmiah, review, publikasi hingga diseminasi informasi kepada masyarakat ilmiah. Perpustakaan dalam dunia komunikasi ilmiah telah terlibat dalam proses penyediaan informasi untuk penciptaan karya ilmiah, penghimpun dan penyimpan hasil karya penyerbarluasan informasi hasil karya ilmiah. Namun merupakan sebuah tantang apabila pihak perpustakaan dapat berpartisipasi aktif dalam prosesnya seperti sebagai media publikasi dan reviewer karya ilmiah. Maka untuk dapat aktif dalam ranah tersebut, dibutuhkan pustakawan yang handal, adaptable serta memiliki passion untuk bergelut dalam komunikasi ilmiah. Tentunya untuk dapat menjadi apa yang dibutuhkan pustakawan harus memiliki komptensi dasar untuk dapat menjadi scholarly communication librarian. Oleh karenanya dibutuhkan kerja keras dan kemauan yang besar untuk bisa menjadi scholarly communication librarian sehingga dapat meningkatkan prestise profesi ini.
\end{abstract}

Kata Kunci : pustakawan, Komunikasi Ilmiah 


\begin{abstract}
Scholarly communication is a new trend for the library world. Although if examined Scholarly communication is not new in the world of college libraries because the library has been involved in it. Scholarly communication is the process of communicating scholarly papers, reviews, publications to the dissemination of information to the scholarly community. Libraries in the world of scholarly communication have been involved in the process of providing information for the creation of scholarly works, compilers and store of the work of disseminating information from scholarly works. But it is a challenge if the library can actively participate in the process such as the media publication and scholarly work reviewer. So to be active in this domain, librarians who are reliable, adaptable and have a passion for Scholarly communication are needed. Of course to be able to become what is needed by librarians must have basic competence to be able to become a scholarly communication librarian. Therefore it takes a lot of hard work and willingness to become a communication librarian scholarly so that it can increase the prestige of this profession.
\end{abstract}

Keywords : librarian, scholarly communication

\title{
PENDAHULUAN
}

Dunia akademik mengalami perkembangan yang massive dalam hal ini perguruan tinggi, dimana proses pembelajaran bersifat aktif dan menuntut mahasiswa untuk berpikir analitis serta naratif dalam lingkup sharing pengetahuan. Selain itu, dunia pendidikan tinggi juga dituntut untuk menghasilkan penelitian-penelitian terbaru dan hasil pemikiran analitis yang kemudian dipublikasikan sebagai proses diseminasi pengetahuan. Azura dan Abrrizah $^{1}$ menyatakan bahwa salah satu kriteria dalam evaluasi penilaian dan proses akreditasi perguruan tinggi produktivitas penelitian dan publikasi yang dihasilkan.

Pada saat ini, perguruan tinggi di Indonesia di pacu untuk menghasilkan penelitian dan pemikiran analitik tertulis yang kemudian dipublikasikan pada berbagai jurnal dan konferensi yang nantinya artikelnya dapat terindek

${ }^{1}$ M. H., Azura and A., Abrizah . 2015. Embedded Librarianship in Scholarly Communication: Perceived Roles of Academic Librarians in Malaysian Research Intensive Universities. In: International Conference on Libraries (ICOL) 2015, 25-26 August 2015, Vistana Hotel, Pulau Pinang. pp. 2 
oleh pengindeks bereputasi internasional ${ }^{2}$. Lukman ${ }^{3}$ menyatakan bahwa Indonesia memiliki 20 jurnal terindeks scopus, yang membuat tertinggal dengan Filipina yang memiliki 22 jurnal terindek scopus dan lebih jauh tertinggal dengan Malaysia dengan 79 jurnal terindek scopus.

Akibat yang terjadi adalah perguruan tinggi berlomba-lomba memulai serangkaian kegiatan siklus penelitian mulai dari pencarian data dan informasi, penelitian, penulisan, submit artikel, revisi, publikasi, diseminasi dan kembali lagi. Tentunya dalam siklus tersebut tidak hanya melibatkan satu pihak saja melainkan beberapa pihak, lalu dimana peran perpustakaan perguruan tinggi (perti)?

Siklus tersebut di atas bisa dikatakan sebagai scholarly communication/ komunikasi ilmiah. American Library Association ${ }^{4}$ menyatakan komunikasi ilmiah sebagai sebuah alur yang dimulai dengan penciptaan penelitian dan penulisan ilmiah, selanjutnya dilakukan evaluasi dari segi kualitas, kemudian didesiminasikan kepada masyarakat ilmiah dan disimpan untuk dapat digunakan di masa depan. Berdasarkan penjelasan tersebut dapat digambarkan bahwa perpustakaan berada pada awal penciptaan, diseminasi dan penyimpanan penelitian/ penulisan ilmiah tersebut. Pada tahap awal penciptaan, perpustakaan berperan menyedian sumber informasi dan data yang dibutuhkan guna terciptanya sebuah karya. Pada tahap diseminasi, peran perpustakaan adalah melakukan promosi agar karya ilmiah tersebut digunakan oleh masyarakat dan pada tahap akhir adalah menyimpan karya tersbut untuk jangka waktu panjang untuk dapat digunakan di masa depan.

Untuk dapat melakukan aktivitas tersebut tentunya pihak perpustakaan perti harus memiliki pustakawan yang handal dan adaptable terhadap perubahan yang terjadi. Selain itu, pustakawan perti juga harus dapat aktif dan

${ }^{2}$ Purwoko. 2016. Scholarly Communication: Kompetensi Wajib Pustakawan Perguruan TInggi. Media Informasi, XXV(2), hlm. 103-111. pp. 103

${ }^{3}$ Ibid. pp 103

${ }^{4}$ American Library Association . "Principles and Strategies for the Reform of Scholarly Communication 1", September 1, 2006 tersedia pada http://www.ala.org/acrl/publications/whitepapers/ principlesstrategies (Accessed November 15, 2018) 
keluar dari zona nyamannya yaitu bekerja dibelakang meja teknis dan layanan untuk dapat berperan aktif dalam mendukung scholarly communication di lingkungan perguruan tinggi.

Tulisan ini berusaha menyampaikan gagasan kepada pustakawan tentang skill dan kompetensi apa saja yang dibutuhkan untuk menjadi scholarly communication Librarians yang berpartisipasi aktif, adaptable dan tangguh dalam dunia komunikasi ilmiah

\section{PEMBAHASAN}

\section{Komunikasi Ilmiah}

Online dictionary for library and information science (ODLIS) ${ }^{5}$ mendefinisikan komunikasi ilmiah merupakan sarana komunikasi yang dilakukan sekelompok individu dalam proses penelitian akademik dan penulisan kreatif, yang kemudian hasilnya diinformasikan kepada rekan sejawat secara formal maupun informal. Tradisi ini mulai dikenal di Athena, dimana para akademisi melakukan komunikasi ilmiah dengan cara menulis sebuah monograf dan artikel jurnal untuk dipublikasikan, presentasi papers pada acara konferensi yang kemudian dipublikasikan dalam bentuk prosiding, mengirimkan laporan penelitian sebagai syarat hibah, menciptakan website untuk komunitas akademisi, korespondensi melalui email dan mailing-list. Keseluruhan proses tersebut tidak hanya sekedar penciptaan dan diseminasi hasil karya ilmiah tetapi juga evaluasi kualitas isi oleh rekan sejawat dan pelestarian untuk digunakan di masa depan.

Dalam hal ini, peran perpustakaan perguruan tinggi adalah sebagai fasilitator kegiatan komunikasi ilmiah dalam segala bentuknya. Perpustakaan perguruan tinggi tentunya sebagai gatekeeper informasi yang dihasilkan oleh civitas akademik (civa) dan juga sebagai pelestari agar informasi yang dihasilkan dapat digunakan untuk kepentingan di masa yang akan dating. Perpustakaan perti yang bertugas mendesiminasikan informasi juga berperan

${ }^{5}$ Online dictionary for library and information science tersedia pada https://www.abc-clio. com/ODLIS/odlis_s.aspx 
sebagai media promotor yaitu mempromosikan hasil karya ilmiah agar dibaca oleh masyarakat. Pada era modern saat ini hasil karya ilmiah dapat dipromosikan melalui media website dan social media.

Adanya media online dalam komunikasi ilmiah mmeungkinkan para peneliti untuk melintasi berbagai jenis penelitian yang lebih kompleks dan mempublikasikan karyanya di seluruh dunia. Komunikasi ilmiah memiliki sifat dinamis pada lingkungannya sehingga perpustakaan dan pustakawan dapat mengambil peran baru untuk berpartisipasi aktif di dalamnya. Sanjeeva \& Powdwal $^{6}$ menegaskan bahwa untuk dapat menjadi bagian penting dalam proses penelitian, perpustakaan perlu menerapkan aturan baru termasuk didalamnya menyangkut pengembangan skill dan kompetensi baru bagi pustakawan.

Perpustakaan perti memainkan peran penting dalam proses komunikasi ilmiah dan merespon hal tersebut menjadi trend baru. Komunikasi ilmiah telah menggiring perpustakaan untuk menyediakan layanan dan sumber informasi baru guna memenuhi kebutuhan pengguna. Perpustakaan perti sudah saatnya untuk mengembangkan pengetahuan terkait publikasi, trend tentang pengetahuan serta kriteria tentang evaluasi (melakukan review) pada sebuah publikasi. Perpustakaan perti dapat memulai inisiatif komunikasi ilmiah dengan mengembangkan Repository Institusi.

Selain itu, perpustakaan perti juga dapat mengembangkan penerbitan artikel skripsi mahasiswa menggunakan open journal system (OJS). Adanya surat edaran dari Dikti Nomor 2050/E/T/2011 terkait Kebijakan Unggah Karya Ilmiah dan Jurnal secara online bagi dosen dan mahasiswa bisa menjadi salah satu faktor pengelola perpustakaan mulai mengembangkan repositori institusi dan jurnal online bagi mahasiswa. Dalam kegiatan ini perpustakaan berpartisipasi aktif mulai dari menghimpun karya ilmiah, melakukan review artikel, publikasi dan diseminasi karya ilmiah pada masyarakat.

${ }^{6}$ Meghana Sanjeeva \& Sushama Powdwal . 2018. Skill and Competencies for Scholarly Communication: An Indian Perspective. In IFLA-WLIC 2018, Kuala Lumpur Malaysia, 24th August - 30th August 2018. 


\section{Kompetensi scholarly communication Librarians}

Pustakawan perti harus bersikap adaptable terhadap perubahan pada dunia akademik saat ini. Pustakawan harus selalu meng-upgrade skill dan kompetensinya mengikuti perkembangan dunia pendidikan agar dapat memberikan pelayanan yang terbaik bagi pengguna serta berpartisipasi dalam proses komunikasi ilmiah yang lagi trend saat ini. Auckland ${ }^{7}$ dalam laporan mengemukakan bahwa pustakawan harus menyoroti terkait komunikasi ilmiah sebagai trend yang berkembang saat ini, yang mana akan memberikan sebuah peran baru bagi pustakawan sehingga diperlukan pengembangan skill dan pengetahuan terkait komunikasi ilmiah agar pustakawan dapat memasuki dunia tersebut dengan percaya diri. Bonn ${ }^{8}$ melalui tulisannya menyarakan agar pustakawan perti memiliki kompetensi scholarly communication sebagai kompetensi utama.

Sewell \& Kingsley ${ }^{9}$ menyebutkan membagi skill yang dibutuhkan untuk mendukung penelitian menjadi 2 bagian yaitu discipline specific and generic, transferrable skills. Discipline specific and generic maksudnya adalah pengetahuan spesifik terkait proses penelitian meliputi pengetahuan tentang repository, open access hingga research data management.

Bonn ${ }^{10}$ menambahkan generic skill juga termasuk sikap fleksible dan innovative pustakawan yang bias menjadikan pustakawan merasa nyaman saat bekerja di dunia kerja yang syarat akan perubahan. Transferrable skills berupa keahlian dalam melakukan komunikasi efektif, keahlian dalam memberikan saran, serta keahlian lainnya.

${ }^{7}$ Auckland, M. 2012. Re-skilling for research: An investigation into the role and skills of subject and liaison librarians required to effectively support the evolving information needs of researchers. Tersedia di http://www.rluk.ac.uk/wp-content/uploads/2014/02/RLUK-Re-skilling.pdf.

${ }^{8}$ Bonn, M. (2014). Tooling up Scholarly communication education and training. College \& Research Libraries News, 75(3), 132-135.

${ }^{9}$ Sewell,C \& Kingsley, D (2017) Developing the 21st Century Academic Librarian: The Research Support Ambassador Programme, New Review of Academic Librarianship, 23:2-3, 148-158

${ }^{10}$ Bonn, M. (2014). Tooling up Scholarly communication education and training. College \& Research Libraries News, 75(3), 132-135. 
Wesolek, et all ${ }^{11}$ telah mengkategorikan kompetensi utama yang dibutuhkan pustakawan perti untuk dapat terlibat aktif dalam kegiatan komunikasi ilmiah. Adapun kategori kompetensi tersebut antara lain :

1. Manajemen Repositori Institus

2. Jasa Layanan Publikasi

3. Jasa Layanan Copyright

4. Jasa Layanan Data Management

5. Assement and Impact Metrics

Menurut Calarco, et all ${ }^{12}$ menyatakan dalam komunikasi ilmiah dibutuhkan beberapa kompetensi dalam 4 bidang yaitu :

1. Publikasi ilmiah

2. Repository institusi

3. Copyright dan open access

4. Penilaian akan karya ilmiah dan sumber lainnya

Melihat pengkategorian kompetensi tersebut, maka untuk ikut dalam dunia komunikasi ilmiah pustakawan harus memiliki kompetensi sebagai berikut :

1. Repository Institusi (IR)

- Memiliki pengetahuan tentang kebijakan dan syarat IR

- Memiliki pengetahuan tentang software repository, standar metadata

- Memiliki pengetahuan data format, database design, data management

- Memiliki kemampuan menjalankan platform repository dan update software

- Mampu bertindak sebagai publisher dengan berpengetahuan tentang kebijakan embargo dan artikel berbayar

- Memahami terkait data curation dan preservasi data digital

${ }^{11}$ Wesolek, Andrew, et all.. 2017. NASIG Core Competencies for Scholarly Communication Librarians tersedia di http://www.nasig.org.

${ }^{12}$ Pascal Calarco, Kathleen Shaere, Birgit Schmidt and Dominic Tate. 2016. Librarians' Competencies Profile for Schloarly Communication and Open Access. Joint Task Force on Librarian's Competencies in Support of E-research and Scholarly Communication. 
- Memahami tentang copyright dan lisensi terkait dengan isi karya ilmiah

- Mengikuti perkembangan open access dan scholarly communication

2. Publikasi Ilmiah

- Memiliki pengetahuan tentang publikasi komersil dan open access

- Memiliki pengetahuan tentang proses editorial

- Memiliki pengetahuan tentang DOI, ISSN, ISBN, sitasi

- Memiliki pengetahuan standar metadata dan discovery tools

- Memiliki pengetahuan tentang software OA publishing salah satunya open journal systems (OJS)

3. Copyright

- Memiliki pengetahuan terkait copyrights and licensing seperti creative commons

- Memiliki pengetahuan tentang kebijakan open access

- Memiliki pengetahuan publikasi ilmiah tercetak

4. Data Management

- Memiliki pengetahuan dan kemampuan terkait kebijkan penyimpanan data, akses serta retensi

- Memiliki pengetahuan dan kemampuan tentang open source dan hosting

- Memiliki pengetahuan tentang text and data mining

5. Assessment

- Memiliki pengetahuan tantang indikator impact metrics, seperti bibliometrics

- Memiliki pengetahuan tentang komunitas ilmiah di internet seperti academia.edu, researchgate

- Memiliki pengetahuan tentang impact factors seperti h-index jurnal atau penulis

- Memiliki pengetahuan tentang proses review jurnal baik secara online maupun tradisional 
Purwoko ${ }^{13}$ menuliskan apabila pustakawan ingin terjun dalam dunia komunikasi ilmiah maka diwajibkan memiliki kompetensi berikut ini :

1. Menyusun dan mengelola koleksi subyek terpilih untuk para peneliti.

2. Kemampuan meneliti, dan menuliskan penelitiannya dalam bentuk artikel. Kemampuan ini akan menjadi modal pustakawan dalam ikut membantu pemustaka dalam menulis ilmiah dari penelitian yang dilakukan.

3. Mengetahui aspek teknis dari menulis (template reference management tools, paraphrase).

4. Mengetahui dinamika penerbitan (jurnal predator, open access, impact factor, h-index, SNIP, impact per publication, perankingan jurnal).

5. Plagiat dan cara menghindarinya.

6. Memilih jurnal yang dituju, tips berkomunikasi dengan reviewer dan mengirim artikel ke penerbit (e-jurnal) secara online..

7. Berbagai lisensi tulisan.

8. Pengelolaan karya kelembagaan (repositori institusi).

9. Kemampuan berkomunikasi, dan memberi pelatihan tentang literasi informasi.

\section{Menjadi scholarly communication Librarians}

Dunia komunikasi ilmiah sebenarnya bukan merupakan dunia baru bagi profesi pustakawan. Komunikasi ilmiah sering muncul ketika pustakawan memberikan layanan penelusuran jurnal untuk proses skripsi mahasiswa atau penelitian dosen, terkadang juga muncul ketika mahasiswa meminta konsultasi tentang terkait penulisan ilmiah. Komunikasi ilmiah juga muncul ketika pustakawan mulai menghimpun hasil karya civitas akademika (civa) yang kemudian mulai diolah, disimpan, hingga penyebaran. Namun alangkah bermanfaatnya apabila kita dapat memberikan lebih dari itu, dimana kita bukan hanya sebagai penyedia, tempat penyimpanan serta

\footnotetext{
${ }^{13}$ Purwoko, 2016. Scholarly communication: kompetensi wajib pustakawan perguruan tinggi. Media Informasi, XXV(2), hal. 103-111. Pp. 3-4
} 
penyebaran informasi saja tetapi dapat berpartisipasi aktif di dalamnya mulai dari penciptaan, review, publikasi, diseminasi, preservasi hingga promosi.

Wesolek, Andrew, et all ${ }^{14}$.. menyatakan Pustakawan dapat menjadi scholarly communication Librarians dengan memperkuat keahlian personal berikut ini :

1. Kolaborasi. Kemampuan bekerja sama baik dengan pihak dari dalam insitusi maupun dari luar institusi yang memberikan manfaat bagi komunikasi ilmiah di intern institusi.

2. Communication skill. Keahlian komunikasi tidak hanya verbal saja tetapi juga kemampuan menulis.

3. Antusiasme/ ambisi. Antusiame merupakan keinginan kuat untuk terus belajar mengikuti perubahan dalam dunia akademik dan komunikasi ilmiah

4. Generalist. Mulai mengakrabkan diri dengan dunia publikasi dan scholarship (pemberi dana penelitian)

5. Perasaan nyaman dengan perubahan.

6. Personable. Menjadi orang yang menyenangkan baik secara fisik maupun sikap

Untuk dapat memulai dalam dunia komunikasi ilmiah ada beberapa hal yang dapat dilakukan pustakawan agar dapat melangkah dengan percaya diri, antara lain :

1. Perbanyaklah membaca artikel ilmiah, artikel opini dan sejenisnya

2. Sering melakukan kegiatan menulis dan penelitian

3. Aktif mengirimkan hasil penelitian dan pemikiran analisis dalam publikasi jurnal online, media massa, kegiatan call for papers

4. Mengikuti pelatihan terkait pengelolaan jurnal online dan publikasi lainnya

5. Mengikuti pelatihan literasi informasi

${ }^{14}$ Wesolek, Andrew, et all.. 2017. NASIG Core Competencies for Scholarly Communication Librarians tersedia di http://www.nasig.org. 
6. Menggali informasi terkait plagiat dan copyright dan cara menanggulanginya

7. Melakukan diskusi ilmiah dengan tenaga pengajar serta mahasiswa untuk nantinya dapat berkolaborasi melakukan penelitian atau penulisan ilmiah

\section{Penutup}

Memilih terjun dalam dunia komunikasi ilmiah merupakan sebuah tantangan baru bagi profesi pustakawan. Pustakawan memiliki segudang pekerjaan rumah yang harus segera dipilah mana yang dijadikan pilihan akan menjadi pustakawan yang seperti apakah kita. Perkembangan dan perubahan di dunia pendidikan yang begitu signifikan membuat cara pandang profesi pustakawan juga berbeda. Pustakawan harus berfikir bagaimana kita dapat tetap mengikuti arus perkembangan agar tidak tertinggal namun tetap melakukan pekerjaan rumah lainnya seperti pekerjaan teknis dan layanan perpustakaan.

Sebuah era baru, dunia komunikasi ilmiah telah memberikan peluang bagi pustakawan untuk dapat terus eksis dengan melakukan pengembangan skill dan kompetensi. Tantangan untuk selalu berubah dan life long learning harus diterapkan dan dipupuk dalam diri pustakawan dan calon pustakawan agar tidak tertingggal dengan paradaban yang semakin cepat laju perubahannya.

\section{Daftar Pustaka}

American Library Association . "Principles and Strategies for the Reform of Scholarly Communication 1", September 1, 2006 tersedia pada http://www.ala.org/acrl/publications/whitepapers/principlesstrategies (Accessed November 15, 2018)

Auckland, M. 2012. Re-skilling for research: An investigation into the role and skills of subject and liaison librarians required to effectively support the evolving information needs of researchers. Tersedia di http:// www.rluk.ac.uk/wp-content/uploads/2014/02/RLUK-Re-skilling.pdf. 
Azura ,M.H., and A., Abrizah . 2015. Embedded Librarianship in Scholarly Communication: Perceived Roles of Academic Librarians in Malaysian Research Intensive Universities. In: International Conference on Libraries (ICOL) 2015, 25-26 August 2015, Vistana Hotel, Pulau Pinang. pp. 2

Bonn, M. (2014). Tooling up Scholarly communication education and training. College \& Research Libraries News, 75(3), 132-135.

Calarco, Pascal, Kathleen Shaere, Birgit Schmidt and Dominic Tate. 2016. Librarians' Competencies Profile for Schloarly Communication and Open Access. Joint Task Force on Librarian's Competencies in Support of E-research and Scholarly Communication.

Online dictionary for library and information science tersedia pada https:// www.abc-clio.com/ODLIS/odlis_s.aspx

Purwoko. 2016. Scholarly Communication: Kompetensi Wajib Pustakawan Perguruan Tinggi. Media Informasi, XXV(2), hlm. 103-111. pp. 103 Sanjeeva, Meghana \& Sushama Powdwal . 2018. Skill and Competencies for Scholarly Communication: An Indian Perspective. In IFLA-WLIC 2018, Kuala Lumpur Malaysia, 24th August - 30th August 2018.

Sewell,C \& Kingsley, D (2017) Developing the 21st Century Academic Librarian: The

Research Support Ambassador Programme, New Review of Academic Librarianship, 23:2-3, 148-158

Surat Edaran Direktorat Jendral Pendidikan Tinggi Nomor Nomor 2050/E/T/2011 terkait Kebijakan Unggah Karya Ilmiah dan Jurnal

Wesolek, Andrew, et all.. 2017. NASIG Core Competencies for Scholarly Communication Librarians tersedia di http://www.nasig.org. 